\title{
The rewarding nature of social interactions
}

\author{
Sören Krach ${ }^{1,2 *}$, Frieder M. Paulus ${ }^{1}$, Maren Bodden ${ }^{2}$ andTilo Kircher ${ }^{1}$
}

1 Department of Psychiatry and Psychotherapy, Philipps-University Marburg, Marburg, Germany

2 Department of Neurology, Philipps-University Marburg, Marburg, Germany

\section{Edited by:}

Andreas Meyer-Lindenberg, Central Institute of Mental Health, Germany

\section{Reviewed by:}

Joshua W. Buckholtz, Vanderbilt

University, USA

${ }^{*}$ Correspondence:

Sören Krach, Department of Psychiatry and Psychotherapy, Philipps-University

Marburg, Rudolf-Bultmann-Str. 8

35033 Marburg, Germany.

e-mail:krachs@med.uni-marburg.de
The objective of this short review is to highlight rewarding aspects of social interactions for humans and discuss their neural basis. Thereby we report recent research findings to illustrate how social stimuli in general are processed in the reward system and highlight the role of Theory of Mind as one mediating process for experiencing social reward during social interactions. In conclusion we discuss clinical implications for psychiatry and psychotherapy.

Keywords: reward, theory of mind, social interaction

\section{INTRODUCTION}

Human societies form a dynamic and complex system, which requires frequent interaction between individuals. According to the "social brain hypothesis" (Dunbar, 1998; Adolphs, 2003) parts of the human neo-cortex have evolved to improve survival in dynamic groups and therefore to process social information. This enables us to successfully mate, raise children, manage relationships, communicate, and understand each other. The significance of social interactions in human behavior is also reflected in several psychiatric disorders where impairments in social interaction are either an integral part of the diagnosis (e.g. autism spectrum disorder, schizophrenia, social phobia etc.) or relevant for experienced psychological strain.

Accordingly, the topic of social interaction has increasingly been addressed in the field of psychiatry and psychotherapy as well as the cognitive neurosciences. The present review provides an overview on recent findings on the rewarding nature of social interactions and discusses its implications with respect to psychiatry.

\section{THE REWARDING CHARACTER OF SOCIAL STIMULI}

The involvement of the mesocorticolimbic pathways in processing reward and addiction has been thoroughly studied in recent years (Insel, 2003; Spreckelmeyer et al., 2009). A central role in these processes is assigned to dopamine projections of the ventral tegmental area to the striatum (Satoh et al., 2003). Evidence from animal studies or in vivo imaging studies in humans indicates that the reward circuit in the basal ganglia, particularly mediated by dopamine, is involved in processing rewarding non-social stimuli such as money, food and psychostimulant drugs (Koob and Le Moal, 1997; Schultz et al., 1997; Knutson et al., 2001; Zink et al., 2004; Izuma et al., 2008). However, it is hypothesized that the underlying neural systems have evolved to facilitate reproductive behavior thus motivating social interactions (Kelley and Berridge, 2002).

There are indeed several empirical studies which support this hypothesis and indicate that social reward is processed in the same subcortical network as non-social reward and drug addiction. Several studies in rodents highlight the importance of striatal dopamine for highly socially motivated behavior such as maternal care, mating behavior and social attachment. For instance, the access to pups is more reinforcing than cocaine in female rats (Insel, 2003) and dopamine in the nucleus accumbens (NAcc) is involved in typical mating behavior and social interactions of monogamous praire voles (Wang and Aragona, 2004; Liu et al., 2010).

Data from functional imaging studies in humans exhibit striatal activations for a variety of rewarding social stimuli such as beautiful faces (Aharon et al., 2001), positive emotional expressions (Rademacher et al., 2010), own social reputation (Izuma et al., 2008) and maternal and romantic love (Bartels and Zeki, $2000,2004)$. Additionally, a recent study has shown activation of the nucleus accumbens (NAcc), the putamen and thalamic nuclei during the anticipation of positive social feedback (Spreckelmeyer et al., 2009). These findings are in line with activations found for anticipation of non-social outcomes such as money (Knutson et al., 2000) or food (McClure et al., 2007) and highlight the salience and motivational potential of social stimuli.

Altogether, there is evidence from a variety of studies that the dopaminergic reward circuits in the basal ganglia form the primary neural system for processing reward of various social stimuli which could motivate social behavior. However, reward processing of social stimuli is certainly more complicated than dopamine release in the striatum on its own. First, with regard to neurochemical processes other neurotransmitters, e.g. excitatory amino acids or neuropeptides, such as oxytocin may modulate activity in these circuits (Insel, 2003; Skuse and Gallagher, 2009).

Second, in natural situations, social reward is embedded in complex environments and, hence is strongly dependent on the situational context. This implicates that social interaction must not inherently be rewarding due to the appearance of a positive social stimuli (e.g. smiling face). In a competitive interaction an outplayed counterpart may display sorrow, which likewise would be processed as a rewarding stimulus. Thus, mere salience and anticipation of social incentives is not sufficient; rather, the rewarding nature of the social stimuli depends on their processing on the side of the recipient. Accordingly, the experience of rewarding 
interpersonal communication integrates appearance of social stimuli but further comprises the mental processing and interpretation of these stimuli.

\section{INTERPRETATION OF SOCIAL INTERACTION REQUIRES THEORY OF MIND}

Inferring the mental states of a counterpart, an ability often labeled as having a Theory of Mind (ToM), is one of the core mental processes to enable successful human communication (Adolphs, 2003). Empathic appreciation and acknowledgement of the listener's emotional state (affective ToM) as well as a more rational inference of others' intentions, thoughts, and desires (cognitive ToM) facilitate mutual understanding and deepens social relationships (ShamayTsoory et al., 2007). Thus having a ToM is a prerequisite in successful human social interaction. As described above, potential positive social interactions offer a wide variety of rewarding stimuli for human beings. In a recent fMRI study examining human-robot interaction, participants even indicated having enjoyed direct social interactions with anthropomorphic robots (Krach et al., 2008). Further, this enjoyment was correlated with the amount of humanlikeness of the interaction partner. As such, it is reasonable that decoding mental states of interaction partners (ToM) in general provides a means to gain social benefit from these interactions. This in turn is the process that is valued as rewarding.

Neuroanatomically, the medial prefrontal cortex, the superior temporal sulcus, the temporo-parietal junction and the amygdala have been implicated in mental state attribution processes (Frith and Frith, 1999; Adolphs, 2003). As the physiological basis of mentalizing the impact of dopamine release on ToM has been discussed (Abu-Akel, 2003). Further, a link between the basal ganglia, comprising the substantia nigra which contains most of the dopaminergic neurons, and ToM has been made (Bodden et al., 2010). Accordingly ToM deficits have been described in schizophrenia (Sprong et al., 2007) and Parkinson's disease (Mengelberg and Siegert, 2003; Péron et al., 2009), both associated with dysfunctions of the dopaminergic system. Notably, not only social stimuli activate striatal circuits but to a similar degree these structures are implicated by direct social interactions and mutual cooperation (Rilling et al., 2002).

In sum, dopamine is involved in the prediction and mediation of rewarding stimuli ("life's pleasures") (Schultz, 2001), whereas successful social interactions comprise some of the most potent rewarding stimuli for human beings. It could be a promising approach to examine both, processing of social reward and ToM in a coherent framework considering the potential overlap in functional anatomy and involved neurochemical substrates. Especially the neuropeptide oxytocin, which has often been discussed in the context of animal models for social reward (Liu et al., 2010), has recently been associated with impairments in ToM and accordingly its presence is assumed to facilitating mentalizing processes. Skuse and Gallagher hypothesized that an interaction of both, dopamine and oxytocin, underlies and respectively enables successful and as such rewarding human social interaction (Skuse and Gallagher, 2009).

\section{CLINICAL IMPLICATIONS}

Various psychiatric disorders are characterized by difficulties in social interactions; whereas patients with borderline personality disorder have, e.g. difficulties to maintain social relationships, patients with social phobia are afraid to initiating social interactions or patients with schizophrenia who misinterpret social cues. Both, in patients with autism spectrum disorder and patients with schizophrenia the reduced capability to developing ToM is considered as a pivotal deficit (Baron-Cohen et al., 1985; Sprong et al., 2007).

Furthermore, difficulties in engaging into functional social relationships or partnerships are common in schizophrenia and autism. These patients are less interested in social relationships, and hence do not experience the rewarding character of close relationships. Similar to the decreased consumption of food or sex which is observed in rats being under dopamine blockage (Lopez and Ettenberg, 2001), it is hypothesized that the hedonic pleasure of engaging in social interactions may not be valued as less positive per se, but as their salience is diminished, the drive to engage into social interactions is lacking (Berridge and Robinson, 1998). Similarly, in autism spectrum disorder the motivation to engage into social interactions is reduced, however, here the scarcity of oxytocin has been related to the ToM deficits. Accordingly, oxytocin is targeted as one of the most encouraging drug treatments in autism spectrum disorder which potentially helps to enhance social skills and facilitates communication abilities (Bartz and Hollander, 2008).

\section{MENTALIZATION DURING PSYCHOTHERAPY}

The relationship between psychotherapist and patient plays an important role in different therapeutic approaches, and further, it is seen as one of the best predictors of treatment outcome. As outlined above, ToM can be seen as one crucial prerequisite of functional human interaction, and appropriate ToM deepens social relationships. During the therapeutic process patients might appreciate the therapist's behavior and statements to some extent biased, especially when their experiences or mental schemata affect their perception. Sometimes, patients fail in mentalizing, and have difficulties to interpret reality accurately. This can be seen when a patient with social phobia tends to notice negative evaluative beliefs of the other people or when patients with borderline personality disorder tend to interpret facial expressions of other persons more hostile than healthy controls (Dyck et al., 2009).

To gather patient's inner world of thoughts, e.g. how his or hers learning history and past experiences imbue thinking and future experiences or how possible dysfunctional cognitions or mental schemata influence a patient's perception, the therapist engages in mentalizing during the therapy. Thus, mentalizing is a central part in the therapeutic process. Specific therapeutic approaches as "mentalization based treatment" (Allen et al., 2008) account for the improvement of patients' mentalizing abilities as an important part of the therapeutic procedure. As such, it might be speculated that the psychotherapeutic process enables the patient to enhance the experience of rewarding aspects of social interactions. Increasing mentalizing abilities can be associated with therapeutic success and well-being. Furthermore, it should be noted that psychotherapy outcome will be improved by increased mentalizing abilities in both, the therapist and the patient (Allen et al., 2008).

In summary we have argued that successful social interaction can provide one of the most rewarding stimuli for humans. Appearance of social stimuli does not sufficiently mediate the rewarding character of social interactions without the process of perspective taking 
in the recipient which is regarded as a crucial component in order to decode the rewarding character of social interactions. Hence, patients with various psychiatric disorders have difficulties in

\section{REFERENCES}

Abu-Akel, A. (2003). The neurochemical hypothesis of 'theory of mind'. Med. Hypotheses 60, 382-386.

Adolphs, R. (2003). Cognitive neuroscience of human social behaviour. Nat. Rev. Neurosci. 4, 165-178.

Aharon, I., Etcoff, N., Ariely, D., Chabris, C. F., O'Connor, E., and Breiter, H. C. (2001). Beautiful faces have variable reward value: fMRI and behavioral evidence. Neuron 32, 537-551.

Allen, J. G., Fonagy, P., and Bateman, A. W. (2008). Mentalizing in Clinical Practice. Arlington, VA: American Psychiatric Publishing.

Baron-Cohen, S., Leslie, A. M., and Frith, U. (1985). Does the autistic child have a "theory of mind"? Cognition 21,37-46.

Bartels, A., and Zeki, S. (2000). The neural basis of romantic love. Neuroreport 11, 3829-3834.

Bartels, A., and Zeki, S. (2004). The neural correlates of maternal and romantic love. Neuroimage 21, 1155-1166.

Bartz, J. A., and Hollander, E. (2008). Oxytocin and experimental therapeutics in autism spectrum disorders. Prog. Brain Res. 170, 451-462.

Berridge, K. C., and Robinson, T. E. (1998). What is the role of dopamine in reward: hedonic impact, reward learning, or incentive salience? Brain Res. Brain Res. Rev. 28, 309-369.

Bodden, M., Dodel, R., and Kalbe, E. (2010). Theory of mind in Parkinson's disease and related basal ganglia disorders: a systematic review. Mov. Disord. 25, 13-27.

Dunbar, R. M. (1998). The social brain hypothesis. Evol. Anthropol. 6, 178-190.

Dyck, M., Habel, U., Slodczyk, J., Schlummer, J., Backes, V., Schneider, F. and Reske, M. (2009). Negative bias in fast emotion discrimination in borderline personality disorder. Psychol. Med. 39, 855-864.

Frith, C. D., and Frith, U. (1999). Interacting minds - a biological basis. Science 286, 1692-1695.

Insel, T. R. (2003). Is social attachment an addictive disorder? Physiol. Behav. 79, 351-357.

Izuma, K., Saito, D. N., and Sadato, N. (2008). Processing of social and monetary rewards in the human striatum. Neuron 58, 284-294.

Kelley, A. E., and Berridge, K. C. (2002). The neuroscience of natural rewards: relevance to addictive drugs. $J$. Neurosci. 22, 3306-3311.

Knutson, B., Adams, C. M., Fong, G. W., and Hommer, D. (2001). Anticipation of increasing monetary reward selectively recruits nucleus accumbens. J. Neurosci. 21, RC159.

Knutson, B., Westdorp, A., Kaiser, E., and Hommer, D. (2000). FMRI visualization of brain activity during a monetary incentive delay task. Neuroimage $12,20-27$.

Koob, G. F., and Le Moal, M. (1997). Drug abuse: hedonic homeostatic dysregulation. Science 278, 52-58.

Krach, S., Hegel, F., Wrede, B., Sagerer, G., Binkofski, F., and Kircher, T. (2008). Can machines think? Interaction and perspective taking with robots investigated via fMRI. PLoS ONE 3, e2597. doi: 10.1371/journal.pone.0002597.

Liu, Y., Aragona, B. J., Young, K. A., Dietz, D. M., Kabbaj, M., MazeiRobison, M., Nestler, E. J., and Wang, Z. (2010). Nucleus accumbens dopamine mediates amphetamineinduced impairment of social bonding in a monogamous rodent species. Proc. Natl. Acad. Sci. U.S.A. 107, 1217-1222.

Lopez, H. H., and Ettenberg, A. (2001). Dopamine antagonism attenuates the unconditioned incentive value

appropriate mentalizing which might detain them to experience the reward character of interactions diminishing the ability to form and maintain functional social relationships.

of estrous female cues. Pharmacol. Biochem. Behav. 68, 411-416.

McClure, S. M., Ericson, K. M., Laibson, D. I., Loewenstein, G., and Cohen, J. D. (2007). Time discounting for primary rewards. J. Neurosci. 27 , 5796-5804.

Mengelberg, A., and Siegert, R. J. (2003). Is theory-of-mind impaired in Parkinson's disease? Cogn. Neuropsychiatry 8, 191-209.

Péron, J., Vicente, S., Leray, E., Drapier, S., Drapier, D., Cohen, R., Biseul, I., Rouaud, T., Le Jeune, F., Sauleau, P., and Vérin, M. (2009). Are dopaminergic pathways involved in theory of mind? A study in Parkinson's disease. Neuropsychologia 47, 406-414.

Rademacher, L., Krach, S., Kohls, G., Irmak, A., Gründer, G., and Spreckelmeyer,K. (2010).Dissociation of neural networks for anticipation and consumption of monetary and social rewards. Neuroimage 49 , 3276-3285.

Rilling, J.K., Gutman, D., Zeh, T., Pagnoni, G., Berns, G., and Kilts, C. (2002). A neural basis for social cooperation. Neuron 35, 395-405.

Satoh, T., Nakai, S., Sato, T., and Kimura, M. (2003). Correlated coding of motivation and outcome of decision by dopamine neurons. J. Neurosci. 23 , 9913-9923.

Schultz, W. (2001). Reward Signaling by Dopamine Neurons. Neuroscientist 7, 293-302.

Schultz, W., Dayan, P., and Montague, P. R. (1997). A neural substrate of prediction and reward. Science 275 1593-1599.

Shamay-Tsoory, S. G., Shur, S., BarcaiGoodman,L., Medlovich, S., Harari,H., and Levkovitz, Y. (2007). Dissociation of cognitive from affective components of theory of mind in schizophrenia Psychiatry Res. 149, 11-23.
Skuse, D. H., and Gallagher, L. (2009). Dopaminergic-neuropeptide interactions in the social brain. Trends Cogn Sci. (Regul. Ed.) 13, 27-35.

Spreckelmeyer, K. N., Krach, S., Kohls, G., Rademacher, L., Irmak, A., Konrad, K., Kircher, T., and Grunder, G. (2009). Anticipation of monetary and social reward differently activates mesolimbic brain structures in men and women. Soc. Cogn. Affect. Neurosci. 4, 158-165. Sprong, M., Schothorst, P., Vos, E., Hox, J., and van Engeland, H. (2007). Theory of mind in schizophrenia: metaanalysis. Br. J. Psychiatry 191, 5-13.

Wang, Z., and Aragona, B. J. (2004). Neurochemical regulation of pair bonding in male prairie voles. Physiol. Behav. 83, 319-328.

Zink, C. F., Pagnoni, G., Martin-Skurski, M. E., Chappelow, J. C., and Berns, G. S. (2004). Human striatal responses to monetary reward depend on saliency. Neuron 42, 509-517.

Conflict of Interest Statement: The authors declare that the research was conducted in the absence of any commercial or financial relationships that could be construed as a potential conflict of interest.

Received: 22 October 2009; paper pending published: 12 January 2010; accepted: 17 April 2010; published online: 28 May 2010

Citation: Krach S, Paulus FM, Bodden M and Kircher T (2010) The rewarding nature of social interactions. Front. Behav. Neurosci. 4:22. doi: 10.3389/fnbeh.2010.00022

Copyright $\odot 2010$ Krach, Paulus, Bodden and Kircher. This is an open-access article subject to an exclusive license agreement between the authors and the Frontiers Research Foundation, which permits unrestricted use, distribution, and reproduction in any medium, provided the original authors and source are credited. 